\title{
An In-Plane Approximated Nonlinear MEMS Electromagnetic Energy Harvester
}

\author{
Huicong Liu, You Qian, Nan Wang, Student Member, IEEE, and Chengkuo Lee, Member, IEEE
}

\begin{abstract}
This paper presents the fabrication, modeling, and characterization of an in-plane approximated nonlinear MEMS electromagnetic energy harvester (EM-EH) device. The approximated nonlinearity and frequency broadening of the device are realized by incorporating small suspension structures, which introduces the spring hardening effect and thus increases the operating frequency of the device toward a higher frequency interval. From the experimental results, the resonant frequencies during frequency up-sweep have been shifted from the original resonance of $82 \mathrm{~Hz}$ to $123.5,135$, and $146.5 \mathrm{~Hz}$, at the accelerations of 1.0, 2.0 and $3.0 \mathrm{~g}$, respectively. The corresponding power densities at resonances are $1.6 \times 10^{-8}, 2.8 \times 10^{-8}$, and $5.6 \times$ $10^{-8} \mathrm{~W} / \mathrm{cm}^{3}$. This paper offers a new design methodology of the approximated nonlinear MEMS EM-EH device. [2013-0080]
\end{abstract}

Index Terms-MEMS, electromagnetic energy harvester, in-plane, nonlinear.

\section{INTRODUCTION}

$\mathbf{R}$ ECENT advances in low power consumption and intelligent wireless sensor networks have led to the rapid emergence of the energy harvesting technology to be an alternative power source of traditional batteries [1]-[4]. A vibrationbased EH [5] scavenges and converts ambient kinetic energy into electric energy based on the conversion mechanisms of piezoelectric [6]-[11], electromagnetic (EM) [12]-[15] and electrostatic (ES) [16]-[19]. A vibration-based EH using resonant mechanism only obtains the optimal power within a narrow bandwidth nearby its resonance. Nevertheless, in the targeted commonly occurring vibration sources such as buildings or industrial machines, the dominant frequency peaks normally vary in a broadband range instead of a single resonant spike [20]-[22]. Such examples have been reported by Wu et al. [23], where the dominant frequency peaks of the vertical fan belts distribute in a range of 20 to $45 \mathrm{~Hz}$, while the vibrations of the HVAC ducts vary in a frequency range of 15 to $80 \mathrm{~Hz}$. In the case that the targeted source vibration is away from the resonance of the designed $\mathrm{EH}$, the power generation is too low to be utilized. As a result, EHs integrated

Manuscript received March 24, 2013; revised August 5, 2013; accepted September 1, 2013. Date of publication October 2, 2013; date of current version May 29, 2014. This work was supported in part by the Faculty Research Committee under Grant R-263-000-692-112 at the National University of Singapore and in part by the NRF-CRP001-057 Program "Self-Powered Body Sensor Network for Disease Management and Prevention-Oriented Healthcare" under Grant R-263-000-A27-281 from the National Research Foundation, Singapore. Subject Editor R. R. A. Syms.

The authors are with the Department of Electrical and Computer Engineering, National University of Singapore, Singapore 117576 (e-mail: bjliuhuicong@gmail.com; eleqy@nus.edu.sg; nan.wang@nus.edu.sg; elelc@nus.edu.sg).

Color versions of one or more of the figures in this paper are available online at http://ieeexplore.iee.org.

Digital Object Identifier 10.1109/JMEMS.2013.2281736 with tunable or broadband mechanisms are considered to address the frequency bandwidth limitation.

Frequency tunable approaches can be achieved by shifting the center of gravity of a proof mass, and varying the effective spring stiffness attributed to magnetic force or mechanical stress [24], [25]. However, additional system or energy is required and the operating frequency needs to be tuned manually. On the other hand, bandwidth broadening solutions have been widely developed mainly by two approaches. A straightforward way is to integrate a series of small harvesters with various dimensions and thus different resonances [26]-[28]. The assembled system has a wide operating frequency range and hence the power spectrum becomes a combination of that of each individual harvester. The other approach is to change the effective spring stiffness of the oscillating system by introducing rigid stoppers or nonlinear springs. Soliman et al. reported an EM-EH prototype assembled with a rigid stopper [29], [30]. The effective stiffness of the system increases suddenly as the cantilever engages with the stopper. This approach increases the up-sweep bandwidth to be wider than that of the prototype without a stopper [31], [32]. Liu et al. have proposed wideband piezoelectric MEMS EHs [33], [34] by using a metal base to suppress the vibration amplitude but to change the stiffness of the piezoelectric microcantilever. The mechanical model has been built and discussed in ref [35]. The nonlinearity efficacy of a suspension structure has been demonstrated by the addition of magnetic reluctance forces [36]-[41]. The use of nonlinear spring structure such as clamped-guided beam induces tensile stress for large displacement and consequently increases spring stiffness [42]-[44]. An in-plane Perfluoropolymer electret generator was reported by Suzuki et al. [45]. They designed the amplitude limiting dampers to realize nonlinear behaviors. Nguyen et al. [46]-[48] have reported another nonlinear ES-EH with strong softening spring effect. Theoretically, a hard nonlinearity will produce an output improvement when the device resonance approaches towards a higher frequency, while a soft nonlinearity will show an output improvement when the device resonance approaches towards a lower frequency. However, most of the reported nonlinear spring structures have a relatively high operating frequency range, normally several hundreds $\mathrm{Hz}$, unless the Si spring structure is replaced by soft polymer material, i.e., parylene [45].

On the other hand, a typical vibration-based EM-EH utilizes a permanent magnet as proof mass attached on a flexible spring structure, while the ambient metal coils are able to generate electricity due to the net displacement between the out-of-plane moving magnet and stationary coils [49], [50]. 


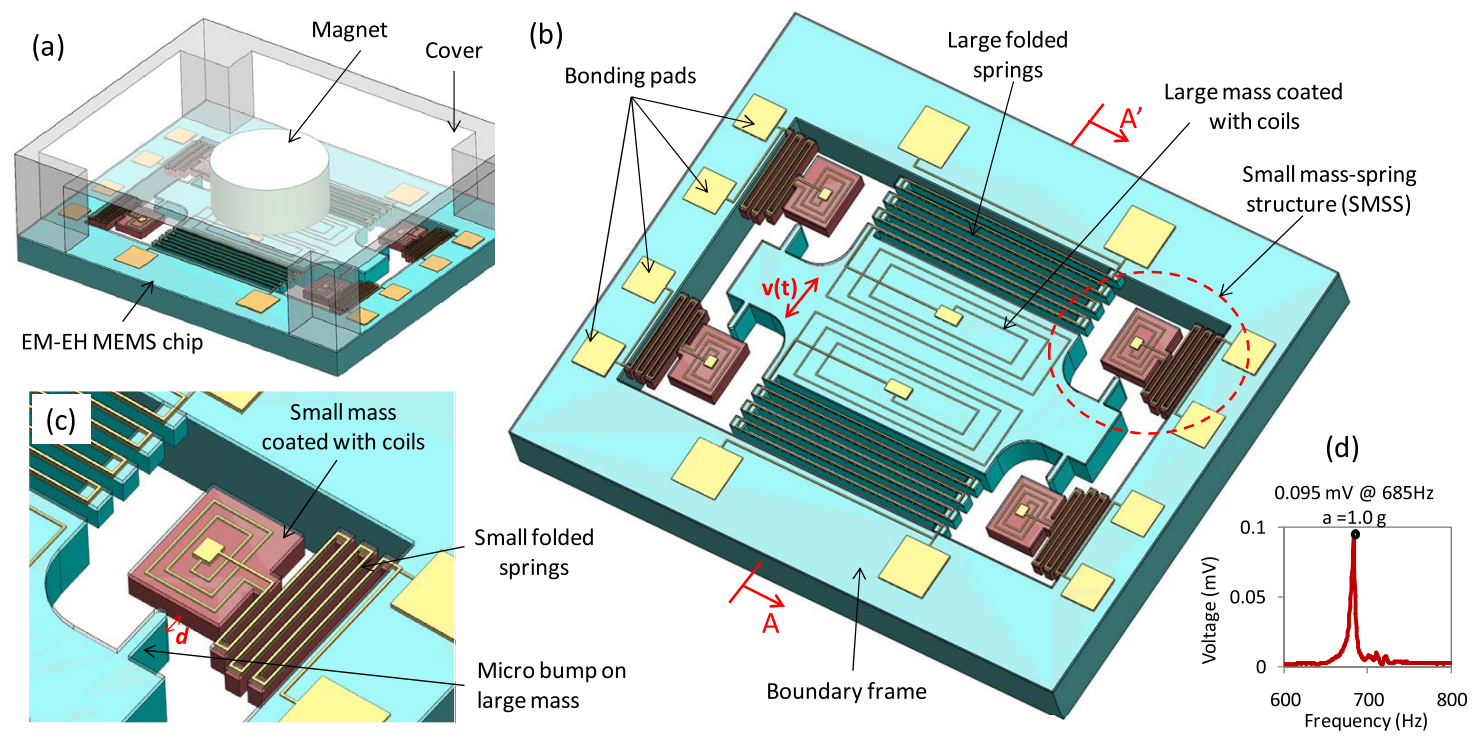

Fig. 1. (a) Schematic drawing of the proposed in-plane broadband MEMS EM-EH device; (b) a schematic perspective view of the MEMS energy harvesting chip; (c) a zoom-in view of the SMSS; (d) measured output voltage against frequency for the SMSS at $1.0 \mathrm{~g}$.

TABLE I

DIMENSION PARAMETERS OF THE LMSS AND SMSS

\begin{tabular}{|l|l|l|}
\hline & LMSS & SMSS \\
\hline Resonant frequency & $82 \mathrm{~Hz}$ & $685 \mathrm{~Hz}$ \\
\hline Mass area & $13.3 \mathrm{~mm}^{2}$ & $0.8 \mathrm{~mm}^{2}$ \\
\hline Mass thickness & $400 \mu \mathrm{m}$ & $150 \mu \mathrm{m}$ \\
\hline Spring thickness & $150 \mu \mathrm{m}$ & $150 \mu \mathrm{m}$ \\
\hline Spring folds & 3.5 & 2.7 \\
\hline Coil loops of each layer & 19 & 10 \\
\hline LMSS dimensions (unit: $\mathrm{mm}$ ) & \multicolumn{2}{|c|}{ SMSS dimensions (unit: $\mathrm{mm}$ ) } \\
\hline
\end{tabular}

However, this architecture is quite difficult to be achieved in wafer-scale due to the relative poor properties of planar magnets and the integration issue of a silicon flexible structure and a bulk magnet. The counterpart approach is to assemble a stationary bulk magnet with a micromachined springmass structure patterned with micro-scale metal coils [51]. In this paper, the authors propose an in-plane MEMS EM-EH device incorporating additional small suspension structures. The approximated nonlinearity of the EM-EH device is realized on a single micromachined silicon chip and does not rely on magnetic force or additional assembled stoppers. By using folded springs and large proof mass, the EM-EH device is capable of achieving a relatively low operating frequency range of less than $200 \mathrm{~Hz}$. It reveals a simple approach of in-plane EM-based energy harvesting with the advantage of broadband operation range in low frequency domain which aims at environmental available vibrations.

\section{DESIGN AND MicRofabRICATION}

\section{A. Device Configuration}

A schematic drawing of the in-plane MEMS EM-EH device is shown in Fig. 1(a). The device consists of a MEMS energy harvesting chip (10 mm long $\times 8 \mathrm{~mm}$ wide $\times 0.4 \mathrm{~mm}$ thick) and a permanent magnet with height of $2 \mathrm{~mm}$ and diameter of $3 \mathrm{~mm}$ attached on an acrylic cover. In Fig. 1(b), the energy harvesting chip contains a large mass-spring structure (LMSS) which is a large movable mass suspended by two large folded springs. Each folded spring contains three and half folds with beam length, width and spacing of $4 \mathrm{~mm}, 30 \mu \mathrm{m}$, and $120 \mu \mathrm{m}$, respectively (as shown in Table I). Two layers of metal coils with coil width of $10 \mu \mathrm{m}$ and spacing of $20 \mu \mathrm{m}$ are spirally patterned on the movable mass and electrically connected to bonding pads via the folded springs. When the LMSS responds to an external in-plane vibration, the induced voltage will be generated due to a relative movement between the in-plane moving coils and the stationary magnet according to Faraday's law of induction.

For the realization of approximated nonlinear behavior, four small mass-spring structures (SMSSs) are incorporated at the four sides of the LMSS. Fig. 1(c) shows a zoom-in view of the SMSS, which contains a small folded spring including 2.7 folds with beam length, width and spacing of $1.5 \mathrm{~mm}$, $30 \mu \mathrm{m}$ and $70 \mu \mathrm{m}$, respectively, and a small mass of $1 \mathrm{~mm}$ long, $0.8 \mathrm{~mm}$ wide, and $0.15 \mathrm{~mm}$ thick. The small mass is patterned with double-layer metal coils for the sake of measuring the resonant frequency of the SMSS. Fig. 1(d) shows that a resonant peak of $0.095 \mathrm{mV}$ is observed at the excitation frequency of $685 \mathrm{~Hz}$ and acceleration of $1.0 \mathrm{~g}$. Since the small 
(a)

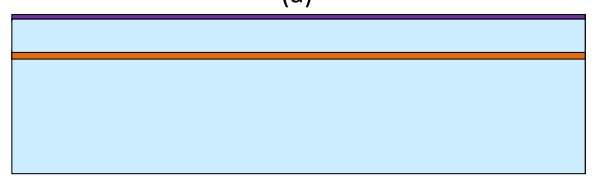

(c)

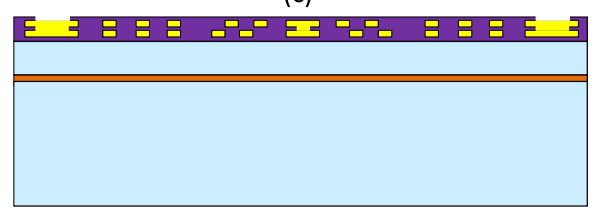

(e)

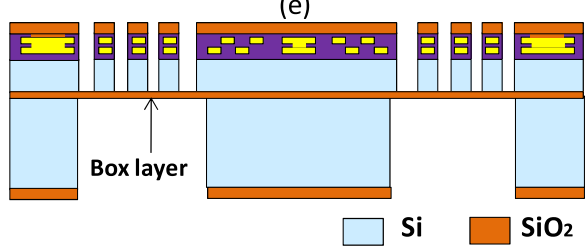

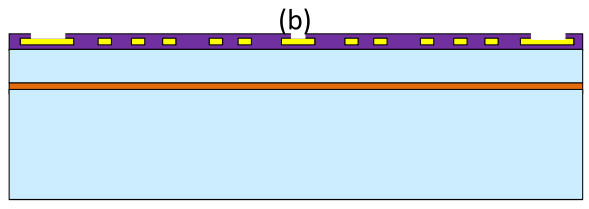

(d)

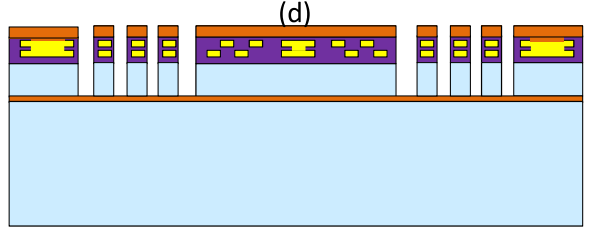

(f)

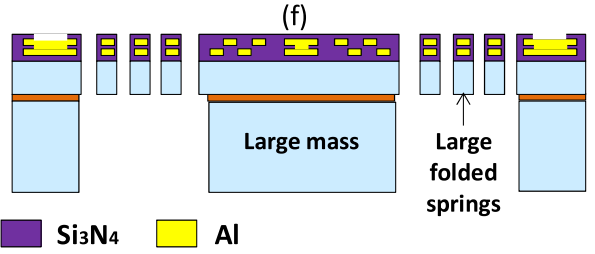

Fig. 2. Microfabrication process of the EM energy harvesting chip. (a) Deposition of $\mathrm{Si}_{3} \mathrm{~N}_{4}$ on the front side of the SOI wafer; (b) Deposition and patterning of the $1^{\text {st }}$ Al layer (Mask 1) followed by $\mathrm{Si}_{3} \mathrm{~N}_{4}$ deposition and via opening (Mask 2); (c) Deposition and patterning of the $2^{\text {nd }}$ Al layer (Mask 3 ) followed by $\mathrm{Si}_{3} \mathrm{~N}_{4}$ deposition and contact opening (Mask 4); (d) Deposition of $\mathrm{SiO}_{2}$ followed by frontside feature patterning and DRIE (Mask 5); (e) Wafer grounding followed by $\mathrm{SiO}_{2}$ patterning (Mask 6) and backside DRIE stopped on the BOX layer; (f) Dry etch of $\mathrm{SiO}_{2}$ to release the device.

mass area is quite small and it is far away from the magnetic field center, the power generator of the SMSS is negligible comparing to that of the LMSS. The initial gap distance $d$ between the small mass and the micro bump on the large mass is designed as small as $80 \mu \mathrm{m}$. As long as the linear oscillator of LMSS deflects over the initial gap distance of $80 \mu \mathrm{m}$, the SMSSs will be engaged and induce spring stiffening effect on the LMSS. Thus the linear oscillators of SMSSs are serving as small suspensions for the enforcement of approximated nonlinear behavior of the LMSS. The dimension parameters of the LMSS and SMSS are summarized and illustrated in Table I.

\section{B. Microfabrication}

Figure 2 shows a microfabrication process flow of the energy harvesting chip across the section A-A' (indicated in Fig. 1). It starts from a silicon-on-insulator (SOI) wafer with a $150 \mu \mathrm{m}$ thick Si device layer, a $1 \mu \mathrm{m}$ thick buried oxide (BOX) layer, and a $725 \mu \mathrm{m}$ thick Si handle layer. As shown in Fig. 2(a), a $0.1 \mu \mathrm{m}$ thick insulating plasma-enhanced chemical vapor deposition (PECVD) silicon nitride $\left(\mathrm{Si}_{3} \mathrm{~N}_{4}\right)$ layer is first deposited on the frontside surface of the SOI wafer. A $1 \mu \mathrm{m}$ thick aluminum (Al) layer is subsequently deposited by physical vapor deposition (PVD) and patterned by reactive ion etching (RIE) to form the electromagnetic coils and bonding pads through Mask 1 . This is followed by the deposition and via opening of a $0.8 \mu \mathrm{m}$ thick PECVD $\mathrm{Si}_{3} \mathrm{~N}_{4}$ insulation layer through Mask 2 as shown in Fig. 2(b). Similar to the first coil layer process, $1 \mu \mathrm{m}$ thick $\mathrm{Al}$ and $0.8 \mu \mathrm{m}$ thick $\mathrm{Si}_{3} \mathrm{~N}_{4}$ are again deposited, patterned and etched in Fig. 2(c) to form the second coil layer and contact pads through Masks 3 and 4. In Fig. 2(d), a $2 \mu \mathrm{m}$ thick silicon dioxide $\left(\mathrm{SiO}_{2}\right)$ layer is then deposited on the top surface as a passivation
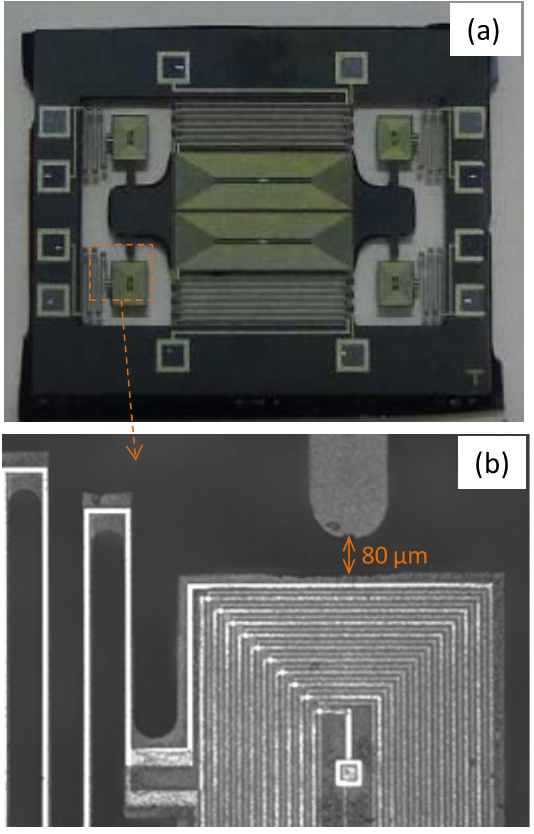

Fig. 3. (a) Photograph of the fabricated MEMS energy harvesting chip; the inset figure shows a top view of the assembled MEMS EM-EH device; (b) microscope image of the SMSS and micro bump with a gap distance of $80 \mu \mathrm{m}$.

layer. Through Mask 5, the $\mathrm{SiO}_{2}$ layer is patterned as a hard mask together with the photoresist (PR) for further RIE of the $\mathrm{Si}_{3} \mathrm{~N}_{4}$ using $\mathrm{CF}_{4}$. It is followed by deep reactive ion etching (DRIE) of the $150 \mu \mathrm{m}$ thick Si device layer to define the frontside silicon features, i.e. the LMSS and SMSSs of the energy harvesting chip

After all the frontside processes are completed, a backside grinding and polishing of the SOI wafer is conducted. The thickness of the Si handle layer is reduced from $725 \mu \mathrm{m}$ to 
$300 \mu \mathrm{m}$ and thus the whole thickness of the SOI wafer is reduced to be approximately $450 \mu \mathrm{m}$. In Fig. 2(e), a $2 \mu \mathrm{m}$ thick PECVD $\mathrm{SiO}_{2}$ is then deposited on the backside of the wafer and a thick PR layer is patterned through Mask 6. Both the PR and $\mathrm{SiO}_{2}$ can function as resist layers for the subsequent backside Si DRIE process to a depth of approximately $250 \mu \mathrm{m}$. To ensure that the entire backside $\mathrm{Si}$ is fully etched away, several fine DRIE steps of five minutes each are conducted to gradually remove the remaining Si handle layer of $50 \mu \mathrm{m}$. Eventually the DRIE process is terminated at the BOX layer and a final release process including dry etching of the remaining $\mathrm{SiO}_{2}$ on the frontside and BOX layers by $\mathrm{CHF}_{3}$ plasma is conducted in Fig. 2(f). Figure 3(a) shows the fabricated MEMS energy harvesting chip. An enlarged view of the SMSS and micro bump with a gap distance of $80 \mu \mathrm{m}$ is shown in Fig. 3(b). The energy harvesting chip is wire-bonded onto a dual-in-line package (DIP). A cylindrical neodymium $(\mathrm{NdFeB})$ magnet is attached to an acrylic cover and is placed on top of the chip center with a gap distance of $1 \mathrm{~mm}$.

\section{Modeling}

\section{A. Electro-Magnetic Model}

According to Faraday's law of induction, the induced voltage of the in-plane EM-EH device is proportional to the negative rate of change of the magnetic flux. It can further be expanded as a general expression which is a combination of both the negative terms of the rate of change of the magnetic flux density and the magnetic field area in a winding coil as:

$$
\varepsilon=-\frac{d \Phi}{d t}=-\sum_{i=1}^{n} \frac{d \vec{B}}{d t} \cdot \vec{A}_{i}-\sum_{i=1}^{n} \vec{B} \cdot \frac{d \vec{A}_{i}}{d t}
$$

where $\varepsilon$ is the electromotive force (emf) of a winding coil; $t$ is the time; $\Phi$ is the magnetic flux; B is the magnetic flux density. $i$ is the coil loop order; $A_{i}$ is the magnetic field area included in the $i$-th loop; and $n$ is the total loop numbers of a winding coil. For the LMSS, there are two winding coils symmetrically patterned on the large movable mass. Each winding coil consists of two layers and each layer contains 19 loops. Due to the in-plane movement of the LMSS, the magnetic flux density through a winding coil is assumed to be uniform as $\vec{B}$ in an effective area $\vec{A}$. Hence, the first term of Eq. (1) can be ignored in the calculation as:

$$
\varepsilon=-\vec{B} \sum_{i=1}^{n} \frac{d \vec{A}_{i}}{d t}
$$

For a cylindrical permanent magnet, the magnetic flux density $B$ at a distance $d$ is given by [52]:

$$
B=\frac{B_{r}}{2}\left[\frac{(d+h)}{\left[r^{2}+(d+h)^{2}\right]^{1 / 2}}-\frac{d}{\left[r^{2}+d^{2}\right]^{1 / 2}}\right]
$$

where $B_{r}$ is the residual magnetic flux density; $d$ is the gap distance between the magnet and the coils; $r$ and $h$ are the radius and length of the magnet, respectively. Based on Eq. (3), the relationship of the magnetic flux density and the gap distance between the magnet and coils is shown in Fig. 4. The inset figure also indicates the magnetic two-dimensional (2-D) flux line distribution along the cross-section plane by ANSYS.

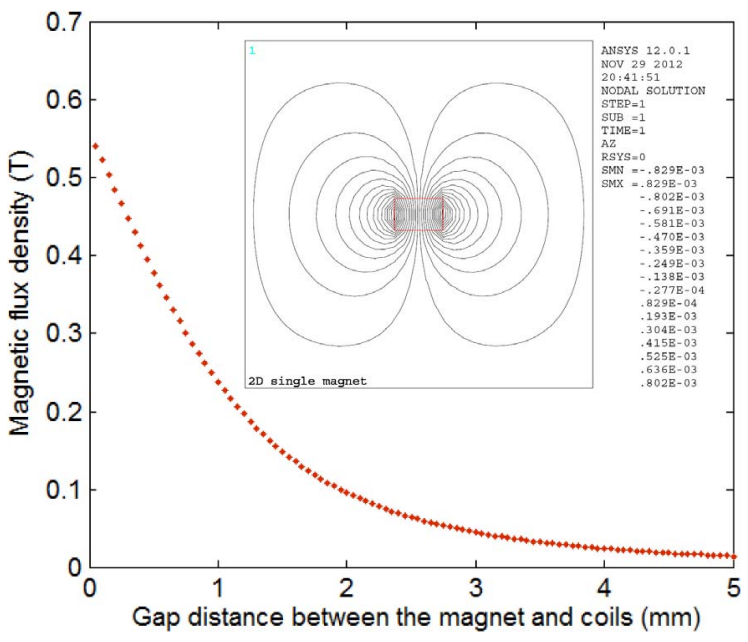

Fig. 4. Relationship of the magnetic flux density and the gap distance between magnet and coils.

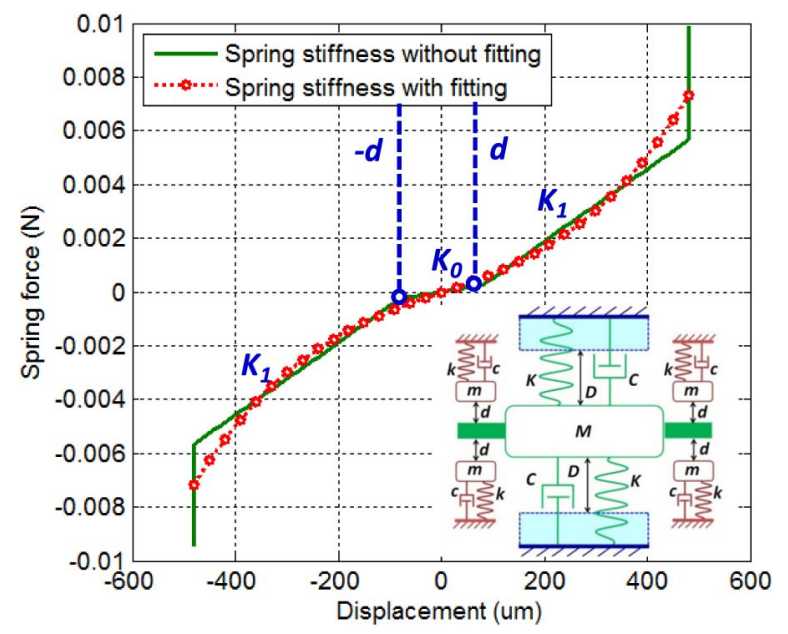

Fig. 5. Spring force versus displacement of the LMSS; inset figure shows the mechanical model of the approximated nonlinear system including a LMSS and four SMSSs as small suspensions.

It is seen that the magnetic flux density decreases as the gap distance increases. At a gap distance of $1 \mathrm{~mm}$, a magnetic flux density of $0.24 \mathrm{~T}$ is obtained by assuming the residual magnetic flux density is $1.4 \mathrm{~T}$. For a specific vibration frequency, the rate of change of the effective area of each coil loop through the magnetic field can be calculated numerically and the induced voltage $\varepsilon_{i n}$ by an in-plane motion is obtained subsequently.

\section{B. Mechanical Model and Simulation}

Figure 5 shows the spring force versus displacement of the LMSS, based on the mechanical model of the approximated nonlinear system with a LMSS and four SMSSs as small suspensions. In the model, the LMSS is considered as a primary suspension system with a proof mass $M$ $\left(12.35 \times 10^{-6} \mathrm{~kg}\right)$ suspended by two folded springs of stiffness $K$ and damper $C$. The maximum allowable displacement $D$ of the LMSS is limited as $480 \mu \mathrm{m}$ when the folded spring 


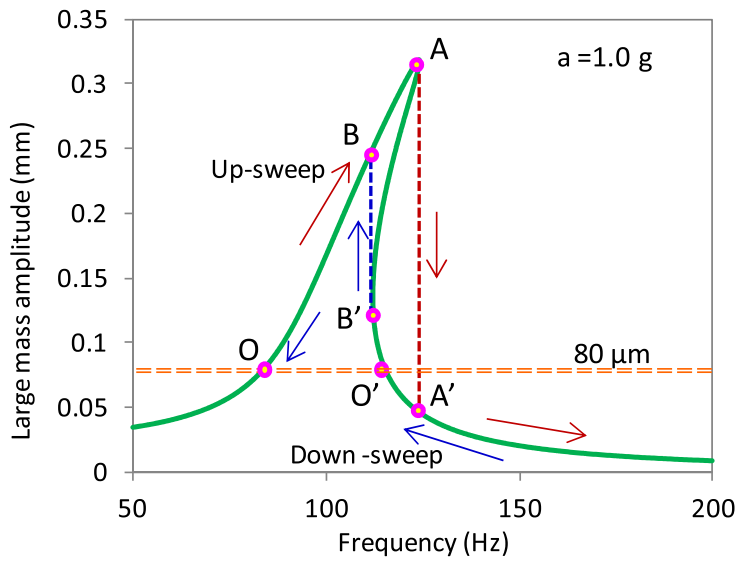

Fig. 6. Simulation results of the vibration amplitude of the large mass against frequency sweeping up and down at an acceleration of $1.0 \mathrm{~g}$.

is packed together at one side. The SMSS is considered as a secondary suspension system with proof mass $m$, spring stiffness $k$, and damping factor $c$. The initial gap distance between the SMSS and large mass is $d$. As the displacement of the large mass $x$ is smaller than the gap distance $d$, the system retains an overall spring stiffness of $K_{0}(3.2 \mathrm{~N} / \mathrm{m})$ which is equivalent to two parallel connected folded springs of stiffness $K$. When the relative displacement is larger than $d$ the engagement of the small suspensions induces the variation of spring stiffness from $K_{0}$ to $K_{1}(13.5 \mathrm{~N} / \mathrm{m})$ until the large mass reaches its displacement limit $D$.

Based on piecewise linear curve of the spring forcedisplacement, curve fitting has been done to approximate the spring stiffness into a nonlinear curve as indicated in a red dash-dotted line in Fig. 5. The spring restoring force $F_{S}$ is represented as $F_{s}=k_{1} x+k_{3} x^{3}$, where $k_{1}$ and $k_{3}$ are fitted as 6.8 and $3.6 \times 10^{7} \mathrm{~N} / \mathrm{m}$, respectively. Such approximated nonlinear force-displacement curve indicates a spring hardening characteristic that the spring restoring force increases more rapidly than the displacement. Higher spring stiffness increases the effective resonant frequency of the LMSS and enables the resonance to shift towards a higher frequency. By using duffing equation of the nonlinear spring-mass system, the displacement of the large mass can be written as:

$$
M \ddot{x}+C \dot{x}+k_{1} x+k_{3} x^{3}=-M \ddot{y}
$$

where $y(t)$ is the external excitation with a vibration amplitude $Y$ and frequency $\omega$, i.e. $y(t)=Y \sin (\omega t)$. The damper $C$ of the nonlinear system can be obtained by $2 \varsigma_{0} \omega_{0}=$ $C / M$, where $\varsigma_{0}$ is the damping ratio of 0.04 and $\omega$ is the resonant frequency of the LMSS. Hence, the vibration amplitude $X$ of the large mass as a function of the excitation frequency can be obtained analytically from Eq. (4) by using MATLAB.

The simulation result of the amplitude of the large mass against frequency sweeping up and down for an acceleration of $1.0 \mathrm{~g}$ is shown in Fig. 6. Initially the amplitude of the large mass follows a linear response curve and increases gradually until it reaches to point $O$, i.e., the initial gap distance of $80 \mu \mathrm{m}$. Henceforward, the large mass starts to engage the
SMSSs and the nonlinear behavior of the LMSS occurs. As the excitation frequency sweeps up, the spectrum appears a notable shift towards a higher frequency interval. The amplitude of the large mass increases monotonically until point $\mathrm{A}$ of $0.32 \mathrm{~mm}$ at $124 \mathrm{~Hz}$. Beyond point A, the amplitude of the large mass drops dramatically to point $\mathrm{A}^{\prime}$ of $0.04 \mathrm{~mm}$ and reverts to the original linear response trace until the sweeping frequency ends up at $200 \mathrm{~Hz}$. As the frequency sweeps down from $200 \mathrm{~Hz}$, the mass amplitude increases gradually through point $\mathrm{A}^{\prime}$, point $\mathrm{O}^{\prime}$ until point $\mathrm{B}^{\prime}$ of 0.13 $\mathrm{mm}$ at $112 \mathrm{~Hz}$. As the frequency continues to sweep down, the large mass amplitude is not able to go to the unstable trace from $\mathrm{B}^{\prime}$ to $\mathrm{A}$ but rises up directly from point $\mathrm{B}^{\prime}$ to $\mathrm{B}$ of $0.25 \mathrm{~mm}$. Thereafter, it follows the nonlinear response trace and decreases through point $\mathrm{O}$ until the end at $50 \mathrm{~Hz}$. In the figure, due to the hard nonlinearity effect, both the upsweep and down-sweep resonant peaks (point A at $124 \mathrm{~Hz}$ and point $\mathrm{B}$ at $112 \mathrm{~Hz}$ ) are shifted greatly from the original resonance of $82 \mathrm{~Hz}$. The corresponding normalized resonance offsets (NRO), which is the resonance offset divided by its original resonance, are achieved to be $51.2 \%$ and $36.6 \%$, respectively. As the excitation acceleration increases, both the amplitude and resonance of the nonlinear system will be increased accordingly.

In this nonlinear response trace, the jump phenomenon can be seen clearly. Points A and B are thus named as jumpdown and jump-up points, respectively, which are actually the resonant frequencies of the nonlinear system during frequency up-sweep and down-sweep. In fact, the jump from $\mathrm{A}$ to $\mathrm{A}^{\prime}$ or from $B^{\prime}$ to $B$ is not instantaneous in time but requires a few cycles of vibration to establish a steady-state vibration at the new amplitude. In the figure, there is an unattainable portion of the response trace in between sections $\mathrm{A}-\mathrm{A}^{\prime}$ and $\mathrm{B}-\mathrm{B}^{\prime}$. There appears to be three possible amplitudes of vibration but only the upper and lower can actually exist. If by some means it is possible to initiate a steady-state vibration with just the proper amplitude and frequency to correspond to the middle branch $\left(\mathrm{A}-\mathrm{B}^{\prime}\right)$, the condition would be unstable. At a slightest disturbance, the motion would jump to either of the other two states of motion. It is thus the hysteresis phenomenon of the frequency response is observed. The up-sweep response has provided a $10.7 \%$ wider bandwidth and a $28 \%$ higher amplitude than those of the down-sweep.

\section{RESUlts AND Discussion}

The broadband behavior of the in-plane MEMS EM-EH device is characterized by using a vibration testing system as shown in Fig. 7. It contains a vibration shaker, a power amplifier, a dynamic signal analyzer, an accelerometer and its controller. The assembled device is attached to the vertical surface of an L-shaped plate and further assembled to the shaker. The vibrations of the mass-spring structures are parallel to the device plane along $\mathrm{z}$-axis and perpendicular to the magnetic field. On the large mass of the LMSS, there are two winding coils symmetrically patterned. Thus the output voltages of the two metal winding coils are collected to the dynamic signal analyzer through channels 1 and 2 and further 


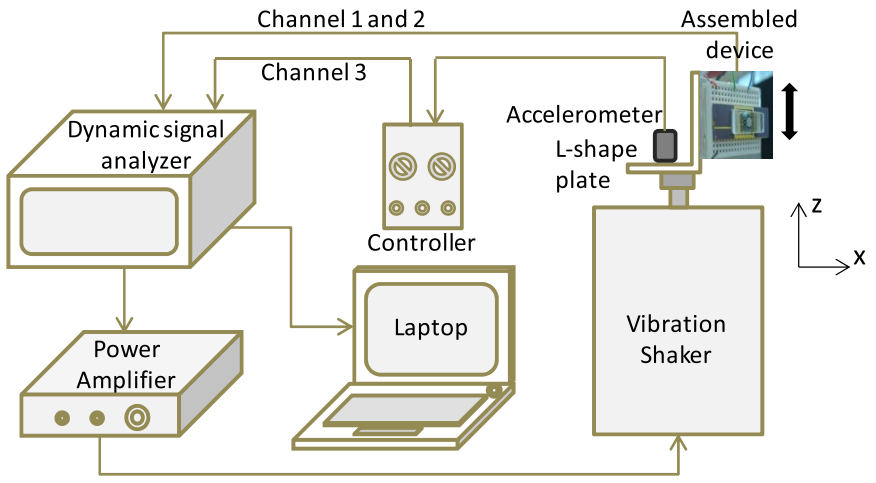

Fig. 7. Schematic illustration of the measurement setup.

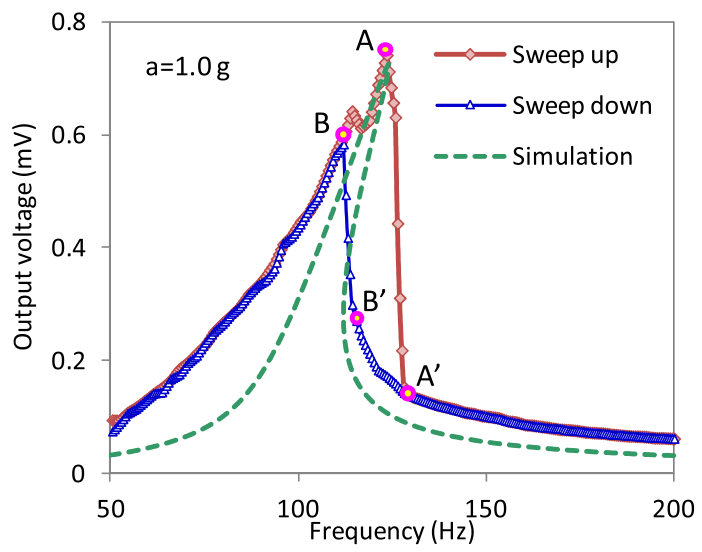

Fig. 8. Measured and simulated output voltage of the EM-EH device for frequency sweeping up and down at an excitation acceleration of $1.0 \mathrm{~g}$.

recorded to the laptop through a GPIB port. An accelerometer is attached to the lateral surface of the L-shape plate for the measurement of $\mathrm{z}$-axis accelerations. The dynamic signal analyzer inputs a sinusoidal signal to the shaker at different frequencies and amplitudes through the power amplifier. The measured acceleration data is collected to the dynamic signal analyzer through channel 3 and further monitored by the laptop.

In the experiment, the excitation frequency is swept up and down in the range of $50-200 \mathrm{~Hz}$ at an excitation acceleration of $1.0 \mathrm{~g}$. Fig. 8 shows the measured output voltage produced by one winding coil of the EM-EH device as indicated by red (up-sweep) and blue (down-sweep) marked lines. It is seen an obvious nonlinear resonance peak offset from the original resonance of $82 \mathrm{~Hz}$ due to the engagement of the SMSSs. From the energy point of view, the part of the vibrational energy absorbed by the LMSS is transferred to the SMSS during the engagement, which results in a loss of energy. Such energy loss is considered to be a large damping of the LMSS resonating with a composite stiffness $K_{1}$ and could result in a reduced voltage output of the device. The up- and downsweeps resonant peaks $\mathrm{A}$ and $\mathrm{B}$ are found to be $0.74 \mathrm{mV}$ at $123.5 \mathrm{~Hz}$ and $0.58 \mathrm{mV}$ at $112 \mathrm{~Hz}$, respectively. The trace dependence for up- and down-sweep is the result of transition of stiffness at the gap distance of $80 \mu \mathrm{m}$.

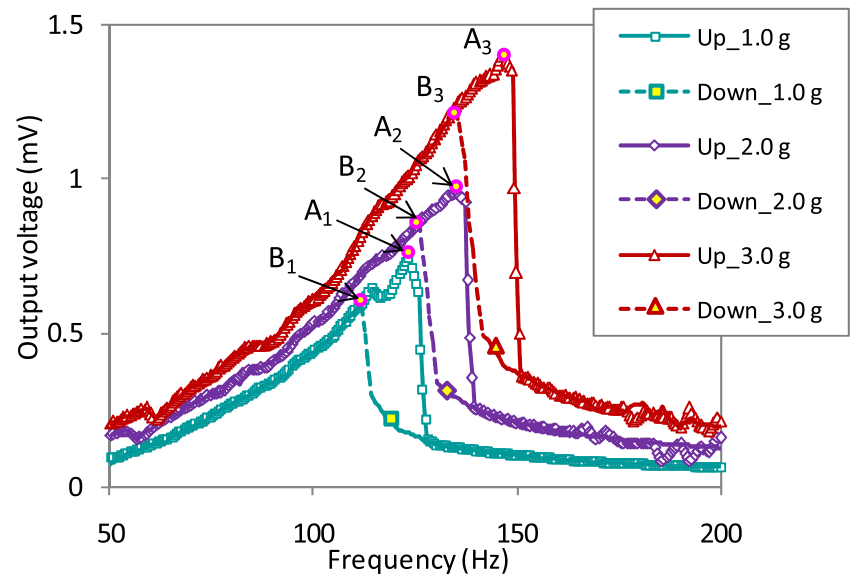

Fig. 9. Output voltage of one winding coil as a function of vibration frequency at different accelerations of $1.0 \mathrm{~g}, 2.0 \mathrm{~g}$ and $3.0 \mathrm{~g}$ for frequency up-sweep and down-sweep.

Based on the previous simulation result of the amplitudefrequency spectrum in Fig. 6, the induced voltage can be obtained from the change of the rate of the magnetic field area included in the winding coils at every frequency point by using Eq. (2). The simulated result indicated in green dashed line is shown in the same figure for comparison. It is observed that there is a good correlation between the measured and simulated values. The simulation trace exhibits a similar resonant offset and voltage peak as the measurement result. However, it appears a relatively higher $\mathrm{Q}$ factor and narrower bandwidth. The discrepancy could be induced by the approximation of the nonlinear spring stiffness in the duffing equation. On the other hand, the simulation parameters such as the damping ratio may not exactly coincide with the measurement condition.

In the same manner, the frequency up- and down-sweeps have been conducted at the excitation accelerations of $2.0 \mathrm{~g}$ and 3.0 g. Fig. 9 shows the output voltages of one winding coil as a function of vibration frequency at these three accelerations. It is obvious that the jump-down and jumpup points are dependent on the excitation amplitude. Higher excitation acceleration leads to higher resonant frequency and output voltage simultaneously. For the frequency up-sweeps, both the output voltages and resonant frequencies of the approximated nonlinear system are increased towards higher values of $0.74 \mathrm{mV}$ at $123.5 \mathrm{~Hz}, 0.96 \mathrm{mV}$ at $135 \mathrm{~Hz}$ and $1.4 \mathrm{mV}$ at $146.5 \mathrm{~Hz}$ (indicated by jump-down points $\mathrm{A}_{1}, \mathrm{~A}_{2}$ and $\mathrm{A}_{3}$ ), respectively, as the acceleration increases from $1.0 \mathrm{~g}, 2.0 \mathrm{~g}$ to $3.0 \mathrm{~g}$. The corresponding NRO have been obtained to be as high as $50.6 \%, 64.6 \%$ and $78.7 \%$. The frequency response of the down-sweep follows a similar trace as that of the upsweep. However, due to the hysteresis phenomenon, the jumpup points $\left(B_{1}, B_{2}\right.$ and $\left.B_{3}\right)$ have relatively lower values than the corresponding jump-down points $\left(\mathrm{A}_{1}, \mathrm{~A}_{2}\right.$ and $\left.\mathrm{A}_{3}\right)$, which are $0.58 \mathrm{mV}$ at $112 \mathrm{~Hz}, 0.86 \mathrm{mV}$ at $125.8 \mathrm{~Hz}$ and $1.22 \mathrm{mV}$ at $135 \mathrm{~Hz}$ at the respective accelerations of $1.0 \mathrm{~g}, 2.0 \mathrm{~g}$ and $3.0 \mathrm{~g}$. It is noted that at the excitation acceleration of $3.0 \mathrm{~g}$, the movement of the LMSS has reached its displacement limit. Hence, the dynamic response of the LMSS will be affected 
TABLE II

Performance of the In-Plane Approximated Nonlinear EM-EH Device at Different Accelerations

\begin{tabular}{ccccc}
\hline Acceleration & Up-sweep & Down-sweep & $\begin{array}{c}\text { Normalized resonance } \\
\text { offset (NRO) }\end{array}$ & Peak power (W) \\
\hline $\mathrm{a}=1.0 \mathrm{~g}$ & $\mathrm{~A}_{1}: 0.74 \mathrm{mV} @ 123.5 \mathrm{~Hz}$ & $\mathrm{~B}_{1}: 0.58 \mathrm{mV} @ 112 \mathrm{~Hz}$ & $50.6 \%$ & $5 \times 10^{-10}$ \\
$\mathrm{a}=2.0 \mathrm{~g}$ & $\mathrm{~A}_{2}: 0.96 \mathrm{mV} @ 135 \mathrm{~Hz}$ & $\mathrm{~B}_{2}: 0.86 \mathrm{mV} @ 125.8 \mathrm{~Hz}$ & $64.6 \%$ & $1.6 \times 10^{-8}$ \\
$\mathrm{a}=3.0 \mathrm{~g}$ & $\mathrm{~A}_{3}: 1.4 \mathrm{mV} @ 146.5 \mathrm{~Hz}$ & $\mathrm{~B}_{3}: 1.22 \mathrm{mV} @ 135 \mathrm{~Hz}$ & $78.7 \%$ & $9 \times 10^{-10}$ \\
\hline
\end{tabular}

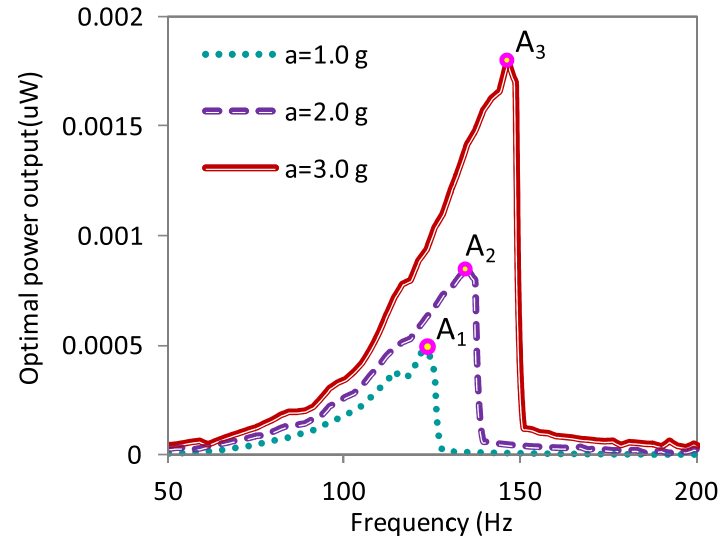

Fig. 10. Overall optimal power as a function of frequency up-sweep at the excitation accelerations of $1.0 \mathrm{~g}, 2.0 \mathrm{~g}$ and $3.0 \mathrm{~g}$.

by the boundary limit afterward. Such effect would suppress the vibration amplitude but broaden the operating bandwidth. The detailed discussion can refer to ref [35]. A summary of the frequency and voltage values of all the jump-down and jumpup points during up- and down-sweeps has been presented in Table II.

By connecting the winding coil with its matched load resistance of $540 \Omega$, the optimal output power can be obtained accordingly. Since the EM-EH device contains two winding coil patterns on the large mass, the overall optimal power as a function of frequency up-sweep are calculated and shown in Fig. 10. The peak power and power density are evaluated in Table II. It is observed that the peak power generated by the EM-EH device for points $\mathrm{A}_{1}, \mathrm{~A}_{2}$ and $\mathrm{A}_{3}$ are increased gradually from $5 \times 10^{-10}$ (at $1.0 \mathrm{~g}$ ), $9 \times 10^{-10}$ (at $2.0 \mathrm{~g}$ ) to $1.8 \times 10^{-9}$ (at $3.0 \mathrm{~g}$ ) W. The corresponding peak power density, which is obtained from the peak power divided by the device volume of $0.032 \mathrm{~cm}^{3}$, are $1.6 \times 10^{-8}, 2.8 \times 10^{-8}$ and $5.6 \times 10^{-8} \mathrm{~W} / \mathrm{cm}^{3}$.

In this work, the small suspensions employed in the in-plane MEMS EM-EH device strengthen the nonlinear hardening effect and thus enable to shift the operating frequency to a higher and wider frequency interval. By comparing with the recent published MEMS-based EHs employing various nonlinear springs as shown in Table III, the proposed EMEH device gains a strong nonlinearity effect and thus a relatively higher NRO of $78.7 \%$ at the acceleration of $3.0 \mathrm{~g}$. Such nonlinear effect is achieved by the design configuration itself without the use of pre-stress or extra force. Comparing with the design of nonlinear beam spring, it normally has a high spring stiffness thus resulting in a high operating
TABLE III

NONLINEARITY EFFECT COMPARISON BETWEEN THIS WORK AND PUblished MEMS-BASEd EHs USING NONLINEAR SPRINGS

\begin{tabular}{cccccc}
\hline Refs. & Method & $\begin{array}{c}\text { Acce. } \\
(\mathrm{g})\end{array}$ & $\begin{array}{c}\text { Center } \\
\text { resonance }(\mathrm{Hz})\end{array}$ & $\begin{array}{c}\text { Shifted } \\
\text { resonance }(\mathrm{Hz})\end{array}$ & NRO \\
\hline$[44]$ & PE & 2 & 1800 & 2450 & $36.1 \%$ \\
{$[45]$} & ES & 1.6 & 45 & 73 & $62.2 \%$ \\
{$[46]$} & ES & 0.16 & 588 & 520 & $11.6 \%$ \\
{$[47]$} & ES & 0.15 & 668 & 560 & $16.2 \%$ \\
This work & EM & 3 & 82 & 146 & $78.7 \%$ \\
\hline
\end{tabular}

TABLE IV

THEORETICAL ESTIMATIONS OF THE POWER GENERATION FOR THE Up-SweEP RESONANCE of Point A 3 In CASES I, II AND III

\begin{tabular}{lccc}
\hline & Case I & Case II & Case III \\
\hline (a) Winding coil layers & 2 & 4 & 6 \\
(b) Magnet gap distance $(\mathrm{mm})$ & 1 & 0.7 & 0.4 \\
(c) Amplitude limit $(\mathrm{mm})$ & 0.48 & 0.75 & 1 \\
\hline Power (W) & $1.8 \times 10^{-9}$ & $1.4 \times 10^{-8}$ & $6.5 \times 10^{-8}$ \\
Power density $\left(\mathrm{W} / \mathrm{cm}^{3}\right)$ & $5.6 \times 10^{-8}$ & $4.3 \times 10^{-7}$ & $2 \times 10^{-6}$ \\
\hline
\end{tabular}

frequency range of about $500-700 \mathrm{~Hz}$ or even several $\mathrm{kHz}$ [44], [46], [47]. One of the main advantages of this design is its relatively low operating bandwidth of less than $200 \mathrm{~Hz}$, which exhibits in the common vibration sources. Moreover, the proposed nonlinear mechanism can be easily adapted to different targeted vibration scenario. To be more specific, the dimension parameters of the folded springs of the LMSS and SMSS can be varied and optimized to realize either a harder or softer spring stiffness of $K_{0}$ and $K_{1}$ based on the practical application. The spring stiffness $K_{0}$ determines the natural frequency of the system and the composite spring stiffness $K_{1}$ of the combination of LMSS and SMSSs affects the nonlinear hardening performance. A low spring stiffness of the small suspension incorporated would weaken the nonlinearity of the system but enable the increment of the output power, while a high spring stiffness of the small suspension would strengthen the nonlinearity effect and enable the device resonance approaching towards a higher frequency interval. The present study offers the design and optimization methodology of realizing frequency broadening and shifting simultaneously, while the presented methodology can be further 
TABLE V

COMPARISON OF MEMS-BASED EM-EHs

\begin{tabular}{llccccc}
\hline \multicolumn{1}{c}{ Refs. } & MEMS Device & $\begin{array}{c}\text { Volume } \\
\left(\mathrm{cm}^{3}\right)\end{array}$ & $\begin{array}{c}\text { Vibration } \\
\text { frequency (Hz) }\end{array}$ & $\begin{array}{c}\text { Vibration } \\
\text { acceleration (g) }\end{array}$ & $\begin{array}{c}\text { Max. } \\
\text { Power (W) }\end{array}$ & $\begin{array}{c}\text { Power density } \\
\left(\mathrm{W} / \mathrm{cm}^{3}\right)\end{array}$ \\
\hline [49] Shearwood et al (1997) & MEMS coil & 0.025 & 4400 & 39 & $3 \times 10^{-7}$ & $1.2 \times 10^{-5}$ \\
[50] Ching et al (2002) & Laser-micromachined spring & 1 & 110 & 9.7 & $8.3 \times 10^{-4}$ & $8.3 \times 10^{-4}$ \\
[51] Mizuno et al (2003) & MEMS coil and spring & -- & 700 & 1.3 & $4 \times 10^{-10}$ & $2 \times 10^{-10}$ \\
[53] Glynne-Jones et al (2004) & Fully assembly & 0.84 & 322 & 5.4 & $3.7 \times 10^{-5}$ & $4.4 \times 10^{-5}$ \\
[54] Koukharenko et al (2006) & MEMS coil and spring & 0.1 & 1600 & 0.4 & $1 \times 10^{-7}$ & $1 \times 10^{-6}$ \\
[55] Pan et al (2006) & MEMS coil and spring & 0.45 & 60 & -- & $1 \times 10^{-4}$ & $2.2 \times 10^{-4}$ \\
[56] Serre et al (2007) & MEMS coil & 0.68 & 360 & 1.7 & $4.5 \times 10^{-8}$ & $6.6 \times 10^{-8}$ \\
[57] Kulkarni et al (2008) & MEMS coil & 0.1 & 60 & 8.8 & $5.86 \times 10^{-7}$ & $5.86 \times 10^{-6}$ \\
[58] Serre et al (2008) & MEMS coil & 1.35 & 382 & 2.9 & $5.5 \times 10^{-5}$ & $4 \times 10^{-5}$ \\
[59] Wang and Arnold (2009) & Fully MEMS & 0.014 & 530 & 1 & $2.3 \times 10^{-11}$ & $1.6 \times 10^{-9}$ \\
[60] Sari et al (2010) & MEMS coil and spring & 0.15 & 113 & $\sim 39 *$ & $6.6 \times 10^{-9}$ & $4.4 \times 10^{-8}$ \\
[61] Cepnik and Wallrabe (2011) & Fully assembly & 0.9 & 142 & 0.1 & $1.2 \times 10^{-5}$ & $1.33 \times 10^{-5}$ \\
[62] Jiang et al (2011) & Fully MEMS & 0.1 & 115 & 1.2 & $1.2 \times 10^{-10}$ & $1.2 \times 10^{-9}$ \\
[63] Zhang et al (2011) & Fully MEMS & 0.078 & 350 & 4.8 & $2 \times 10^{-12}$ & $2.6 \times 10^{-11}$ \\
This work & MEMS coil and spring & 0.032 & 82 & 3 & $1.8 \times 10^{-9}$ & $5.6 \times 10^{-8}$ \\
\hline
\end{tabular}

* Calculated using the formula $a=Y \omega_{0}^{2} / 9.8$ where $a$ is the acceleration

studied and optimized by varying the stiffness and the gap distance of the small suspensions.

It is noteworthy that the power and power density of the present device are relatively low, which leaves us a room to further improve its energy harvesting performance. There are three approaches that can be implemented: (a) increasing the winding coil density and layer; (b) decreasing the gap distance between the magnet and coils; and (c) increasing the amplitude limit of the LMSS. Table IV has summarized the theoretical estimations of the power generation for three different cases (cases I, II and III). Case I shows the varying parameters of the present device, which are winding coil of 2 layers, magnet gap distance of $1 \mathrm{~mm}$, and amplitude limit of $0.48 \mathrm{~mm}$. The power and power density for the up-sweep resonance of point $\mathrm{A}_{3}$ are $1.8 \times 10^{-9} \mathrm{~W}$ and $5.6 \times 10^{-8} \mathrm{~W} / \mathrm{cm}^{3}$, respectively, at the acceleration of 3.0 g. In cases II and III, the winding coils on the large mass is increased to 4 and 6 layers, while the magnet gap distance is decreased to 0.7 and $0.4 \mathrm{~mm}$, respectively. By increasing the spacing of the large folded springs and adjusting the layout, the amplitude limit of the LMSS can be increased from 0.48 to $0.75 \mathrm{~mm}$ (case II) and $1 \mathrm{~mm}$ (case III) under the same volume. Therefore, the theoretical power density for cases II and III at point $\mathrm{A}_{3}$ can be increased greatly to $4.3 \times 10^{-7}$ and $2 \times 10^{-6} \mathrm{~W} / \mathrm{cm}^{3}$, respectively. A comparison of the output performance of the developed device in this work with other published MEMSbased EM-EH devices with a relatively small device volume is given in Table V. Due to the incorporation of small suspensions, the output performance of this work is relatively low, but it has the main advantages of relatively low center frequency of $82 \mathrm{~Hz}$ and strong nonlinearity effect.

\section{CONCluding REMARKS}

This work demonstrates the first prototype of an in-plane MEMS EM-EH device incorporating additional small suspensions. The approximated nonlinear behavior has been investigated in the mechanical model. The experimental results show a qualitative match to the simulation results. At the accelerations of $1.0 \mathrm{~g}, 2.0 \mathrm{~g}$ and $3.0 \mathrm{~g}$, the NRO of the approximated nonlinear EM-EH device has been achieved to be as high as $50.6 \%, 64.6 \%$ and $78.7 \%$, respectively, while the peak power densities of $1.6 \times 10^{-8}, 2.8 \times 10^{-8}$ and $5.6 \times 10^{8} \mathrm{~W} / \mathrm{cm}^{3}$ have been obtained correspondingly. Theoretically, the peak power density can be further improved to be as high as $2 \times 10^{-6} \mathrm{~W} / \mathrm{cm}^{3}$, by increasing the winding coil to 6 layers, decreasing the magnet gap distance to $0.4 \mathrm{~mm}$ and increasing the amplitude limit to $1 \mathrm{~mm}$. The present prototype offers a flexible and feasible design methodology of approximated nonlinear EM-EHs for adapting to the targeted vibration scenarios.

\section{REFERENCES}

[1] S. Roundy, P. K. Wright, and J. M. Rabaey, Energy Scavenging for Wireless Sensor Networks, 1st ed. Boston, MA, USA: Kluwer, 2003.

[2] V. Raghunathan, S. Ganeriwal, and M. Srivastava, "Emerging techniques for long lived wireless sensor networks," IEEE Commun. Mag., vol. 44, no. 4, pp. 108-114, Apr. 2006.

[3] C. O. Mathuna, T. O’Donnell, R. V. Martinez-Catala, J. Rohan, and B. O'Flynn, "Energy scavenging for long-term deployable wireless sensor networks," Talanta, vol. 75, no. 3, pp. 613-623, 2008.

[4] P. D. Mitcheson, E. M. Yeatman, G. K. Rao, A. S. Holmes, and T. C. Green, "Energy harvesting from human and machine motion for wireless electronic devices," Proc. IEEE, vol. 96, no. 9, pp. 1457-1486, Sep. 2008

[5] P. D. Mitcheson, T. C. Green, E. M. Yeatman, and A. S. Holmes, "Architectures for vibration-driven micropower generators," J. Microelectromech. Syst., vol. 13, no. 3, pp. 429-440, Jun. 2004. 
[6] D. Shen, J.-H. Park, J. Ajitsaria, S.-Y. Choe, H.-C. Wikle, and D. J. Kim, "The design, fabrication and evaluation of a MEMS PZT cantilever with an integrated $\mathrm{Si}$ proof mass for vibration energy harvesting," J. Micromech. Microeng., vol. 18, no. 5, pp. 055017-055023, 2008.

[7] R. Elfrink, T. M. Kamel, M. Goedbloed, S. Matova, D. Hohlfeld, Y. van Andel, and R. van Schaijk, "Vibration energy harvesting with aluminum nitride-based piezoelectric devices," J. Micromech. Microeng., vol. 19, no. 9, pp. 094005-1-094005-8, 2009.

[8] B. S. Lee, S. C. Lin, W. J. Wu, X. Y. Wang, P. Z. Chang, and C. K. Lee, "Piezoelectric MEMS generators fabricated with an aerosol deposition PZT thin film," J. Micromech. Microeng., vol. 19, no. 6, pp. 065014-1-065014-8, 2009.

[9] J. C. Park, J. Y. Park, and Y. P. Lee, "Modeling and characterization of piezoelectric $d_{33}$-mode MEMS energy harvester," J. Microelectromech. Syst., vol. 19, no. 5, pp. 1215-1222, Oct. 2010.

[10] T.-T. Yen, T. Hirasawa, P. K. Wright, A. P. Pisano, and L. Lin, "Corrugated aluminum nitride energy harvesters for high energy conversion effectiveness," J. Micromech. Microeng., vol. 21, no. 8, pp. 085037-1-085037-9, 2011.

[11] E. E. Aktakka, R. L. Peterson, and K. Najafi, "Thinned-PZT on SOI process and design optimization for piezoelectric inertial energy harvesting," in Proc. IEEE 16th Int. Solid-State Sensors, Actuat. Microsyst. Conf., Jun. 2011, pp. 1649-1652.

[12] S. Kulkarni, E. Koukharenko, R. Torah, J. Tudor, S. Beeby, T. O'Donnell, and S. Roy, "Design, fabrication and test of integrated micro-scale vibration-based electromagnetic generator," Sens. Actuators A, Phys., vols. 145-146, nos. 1-2, pp. 336-342, 2008.

[13] B. Yang, C. Lee, W. Xiang, J. Xie, J. H. He, R. K. Kotlanka, S. P. Low, and H. Feng, "Electromagnetic energy harvesting from vibrations of multiple frequencies," J. Micromech. Microeng., vol. 19, no. 3, pp. 035001-1-035001-8, 2009.

[14] F. Khan, F. Sassani, and B. Stoeber, "Copper foil-type vibration-based electromagnetic energy harvester," J. Micromech. Microeng., vol. 20, no. 12, pp. 125006-1-125006-11, 2010.

[15] H. Liu, B. W. Soon, N. Wang, C. J. Tay, C. Quan, and C. Lee, "Feasibility study of a 3D vibration-driven electromagnetic MEMS energy harvester with multiple vibration modes," J. Micromech. Microeng., vol. 22, no. 12, pp. 125020-1-125020-11, 2012.

[16] P. Basset, D. Galayko, A. M. Paracha, F. Marty, A. Dudka, and T. Bourouina, "A batch-fabricated and electret-free silicon electrostatic vibration energy harvester," J. Micromech. Microeng., vol. 19, no. 11 , pp. 115025-115036, 2009.

[17] Y. Suzuki, "Recent progress in MEMS electret generator for energy harvesting," IEEJ Trans. Electr. Electron. Eng., vol. 6, no. 2, pp. 101-111, 2011.

[18] T. Masaki, K. Sakurai, T. Yokoyama, M. Ikuta, H. Sameshima, M. Doi, T. Seki, and M. Oba, "Power output enhancement of a vibration-driven electret generator for wireless sensor applications," J. Micromech. Microeng., vol. 21, no. 10, pp. 104004-1-104004-5, 2011.

[19] Y. Feng, K. Hagiwara, Y. Iguchi, and Y. Suzuki, "Trench-filled cellular parylene electret for piezoelectric transducer," Appl. Phys. Lett., vol. 100, no. 26, pp. 262901-1-262901-4, 2012.

[20] S. Roundy, P. K. Wright, and J. Rabaey, "A study of low level vibrations as a power source for wireless sensor nodes," Comput. Commun., vol. 26, no. 11, pp. 1131-1144, 2003.

[21] E. Reilly, L. Miller, R. Fain, and P. K. Wright, "A study of ambient vibrations for piezoelectric energy conversion," in Proc. PowerMEMS, 2009, pp. 312-315.

[22] L. M. Miller, E. Halvorsen, T. Dong, and P. K. Wright, "Modeling and experimental verification of low-frequency MEMS energy harvesting from ambient vibrations," J. Micromech. Microeng., vol. 21, no. 4, pp. 045029-1-045029-13, 2011.

[23] X. Wu, J. Lin, S. Kato, K. Zhang, T. Ren, and L. Liu, "A frequency adjustable vibration energy harvester," in Proc. PowerMEMS, 2008, pp. $245-248$.

[24] V. R. Challa, M. G. Prasad, Y. Shi, and F. T. Fisher, "A vibration energy harvesting device with bidirectional resonance frequency tunability," Smart Mater. Struct., vol. 17, no. 1, pp. 015035-1-015035-10, 2008.

[25] E. S. Leland and P. K. Wright, "Resonance tuning of piezoelectric vibration energy scavenging generators using compressive axial preload," Smart Mater. Struct., vol. 15, no. 5, pp. 1413-1420, 2006.

[26] H. Xue, Y. Hu, and Q. M. Wang, "Broadband piezoelectric energy harvesting devices using multiple bimorphs with different operating frequencies," IEEE Trans. Ultrason., Ferroelectr. Freq. Control, vol. 55, no. 9, pp. 2104-2108, Sep. 2008.
[27] M. Ferrari, V. Ferrari, M. Guizzetti, D. Marioli, and A. Taroni, "Piezoelectric multifrequency energy converter for power harvesting in autonomous microsystems," Sens. Actuators A, Phys., vol. 142, no. 1, pp. 329-335, 2008.

[28] I. Sari, T. Balkan, and H. Kulah, "An electromagnetic micro energy harvester based on an array of parylene cantilevers," J. Micromech. Microeng., vol. 19, no. 10, pp. 105032-105035, 2009.

[29] M. S. M. Soliman, E. M. Abdel-Rahman, E. F. El-Saadany, and R. R. Mansour, "A wideband vibration-based energy harvester," J. Micromech. Microeng., vol. 18, no. 11, pp. 115021-1-115021-11, 2008.

[30] M. S. M. Soliman, E. M. Abdel-Rahman, E. F. El-Saadany, and R. R. Mansour, "A design procedure for wideband micropower generators," J. Microelectromech. Syst., vol. 18, no. 6, pp. 1288-1299, Dec. 2009.

[31] G. Sebald, H. Kuwano, D. Guyomar, and B. Ducharne, "Experimental duffing oscillator for broadband piezoelectric energy harvesting," Smart Mater. Struct., vol. 20, no. 10, pp. 102001-102010, 2011.

[32] A. Narimani, M. F. Golnaraghi, and G. N. Jazar, "Frequency response of a piecewise linear vibration isolator," J. Vib. Control, vol. 10, no. 12, pp. 1775-1794, 2004.

[33] H. Liu, C. J. Tay, C. Quan, T. Kobayashi, and C. Lee, "Piezoelectric MEMS energy harvester for low-frequency vibrations with wideband operation range and steadily increased output power," J. Microelectromech. Syst., vol. 20, no. 5, pp. 1131-1142, Oct. 2011

[34] H. Liu, C. Lee, T. Kobayashi, C. J. Tay, and C. Quan, "A new S-shaped MEMS PZT cantilever for energy harvesting from low frequency vibrations below $30 \mathrm{~Hz}$," Microsyst. Technol., vol. 18, no. 4, pp. 497-506, 2012.

[35] H. Liu, C. Lee, T. Kobayashi, C. J. Tay, and C. Quan, "Investigation of a MEMS piezoelectric energy harvester system with a frequencywidened-bandwidth mechanism introduced by mechanical stoppers," Smart Mater. Struct., vol. 21, no. 3, pp. 035005-1-035005-122, 2012.

[36] B. P. Mann and N. D. Sims, "Energy harvesting from the nonlinear oscillations of magnetic levitation," J. Vib. Control, vol. 319, nos. 1-2, pp. 515-530, 2009.

[37] A. Erturk, J. Hoffmann, and D. J. Inman, "A piezomagnetoelastic structure for broadband vibration energy harvesting," Appl. Phys. Lett., vol. 94, no. 25, pp. 254102-1-254102-3, 2009.

[38] X. Xing, J. Lou, G. M. Yang, O. Obi, C. Driscoll, and N. X. Sun, "Wideband vibration energy harvester with high permeability magnetic material," Appl. Phys. Lett., vol. 95, no. 13, pp. 134103-1-134103-3, 2009.

[39] B. And'o, S. Baglio, C. Trigona, N. Dumas, L. Latorre, and P. Nouet, "Nonlinear mechanism in MEMS devices for energy harvesting applications," J. Micromech. Microeng., vol. 20, no. 12, pp. 125020-1-125020-12, 2010.

[40] S. C. Stanton, C. C. McGehee, and B. P. Mann, "Reversible hysteresis for broadband magnetopiezoelastic energy harvesting," Appl. Phys. Lett., vol. 95, no. 17, pp. 174103-1-174103-3, 2009.

[41] L. Tang and Y. Yang, "A nonlinear piezoelectric energy harvester with magnetic oscillator," Appl. Phys. Lett., vol. 101, no. 9, pp. 094102-1-094102-4, 2012

[42] A. Hajaji and S.-G. Kim, "Ultra-wide bandwidth piezoelectric energy harvesting," Appl. Phys. Lett., vol. 99, no. 8, pp. 083105-1-083105-3, 2011.

[43] M. Marzencki, M. Defosseux, and S. Basrour, "MEMS vibration energy harvesting devices with passive resonance frequency adaptation capability," J. Microelectromech. Syst., vol. 18, no. 6, pp. 1444-1453, Dec. 2009.

[44] L. G. W. Tvedt, D. S. Nguyen, and E. Halvorsen, "Nonlinear behavior of an electrostatic energy harvester under wide- and narrowband excitation," J. Microelectromech. Syst., vol. 19, no. 2, pp. 305-316, Apr. 2010.

[45] D. Miki, M. Honzumi, Y. Suzuki, and N. Kasagi, "Large-amplitude MEMS electret generator with nonlinear spring," in Proc. IEEE 23rd Int. Conf. MEMS, Jan. 2010, pp. 176-179.

[46] D. S. Nguyen, E. Halvorsen, G. U. Jensen, and A. Vogl, "Fabrication and characterization of a wideband MEMS energy harvester utilizing nonlinear springs," J. Micromech. Microeng., vol. 20, no. 12, pp. 125009-125019, 2010.

[47] D. S. Nguyen and E. Halvorsen, "Nonlinear springs for bandwidthtolerant vibration energy harvesting," J. Microelectromech. Syst., vol. 20, no. 6, pp. 1225-1227, Dec. 2011.

[48] D. S. Nguyen, E. Halvorsen, and G. U. Jensen, "Wideband MEMS energy harvester driven by colored noise," J. Microelectromech. Syst., vol. 22, no. 4, pp. 892-900, Aug. 2013. 
[49] C. Shearwood and R. B. Rates, "Development of an electromagnetic microgenerator," Electron. Lett., vol. 33, no. 22, pp. 1883-1884, 1997.

[50] N. N. H. Ching, H. Y. Wong, W. J. Li, P. H. W. Leong, and Z. Wen, "A laser-micromachined multi-modal resonating power transducer for wireless sensing systems," Sens. Actuators A, Phys., vols. 97-98, pp. 685-690, Apr. 2002.

[51] M. Mizuno and D. G. Chetwynd, "Investigation of a resonance microgenerator," J. Micromech. Microeng., vol. 13, no. 2, pp. 209-216, 2003.

[52] T. Zhang, C. Jiang, H. Xu, and J. Mao, "Permanent-magnet longitudinal fields for magnetostrictive devices," J. Appl. Phys., vol. 101, no. 3, pp. 034511-1-034511-3, 2007.

[53] P. Glynne-Jones, M. J. Tudor, S. P. Beeby, N. M. White, and P. French, "An electromagnetic, vibration-powered generator for intelligent sensor systems," Sens. Actuators A, Phys., vol. 110, nos. 1-3, pp. 344-349, 2004.

[54] E. Koukharenko, S. P. Beeby, M. J. Tudor, N. M. White, T. O'Donnell, C. Saha, S. Kulkarni, and S. Roy, "Microelectromechanical systems vibration powered electromagnetic generator for wireless sensor applications," Microsyst. Technol., vol. 12, nos. 10-11, pp. 1071-1077, 2006.

[55] C. T. Pan, Y. M. Hwang, H. L. Hu, and H.C. Liu, "Fabrication and analysis of a magnetic self-power microgenerator," J. Magn. Magn. Mater, vol. 304, no. 1, pp. e394-e396, 2006.

[56] C. Serre, A. Pérez-Rodríguez, N. Fondevilla, J. R. Morante, J. Montserrat, and J. Esteve, "Vibrational energy scavenging with Si technology electromagnetic inertial microgenerators," Microsyst. Technol., vol. 13, nos. 11-12, pp. 1655-1661, 2007.

[57] S. Kulkarni, E. Koukharenko, R. Torah, J. Tudor, S. Beeby, T. O'Donnell, and S. Roy, "Design, fabrication and test of integrated micro-scale vibration-based electromagnetic generator," Sens. Actuators A, Phys., vols. 145-146, nos. 1-2, pp. 336-342, 2008.

[58] C. Serre, A. Pérez-Rodríguez, N. Fondevilla, E. Martincic, S. Martínez, J. R. Morante, J. Montserrat, and J. Esteve, "Design and implementation of mechanical resonators for optimized inertial electromagnetic microgenerators," Microsyst. Technol., vol. 14, nos. 4-5, pp. 653-658, 2008.

[59] N. Wang and D. P. Arnold, "Fully batch-fabricated MEMS magnetic vibration energy harvesters," in Proc. PowerMEMS, 2009, pp. 348-351.

[60] I. Sari, T. Balkan, and H. Kulah, "An electromagnetic micro power generator for low-frequency environmental vibrations based on the frequency upconversion technique," J. Microelectromech. Syst., vol. 19, no. 1, pp. 14-27, Feb. 2010.

[61] C. Cepnik and U. Wallrabe, "A flat high performance micro energy harvester based on a serpentine coil with a single winding," in Proc. IEEE 16th Int. Solid-State Sensors, Actuat. Microsyst. Conf., Jun. 2011, pp. 661-664.

[62] Y. Jiang, S. Masaoka, T. Fujita, M. Uehara, T. Toyonaga, K. Fujii, $\mathrm{K}$. Higuchi, and K. Maenaka, "Fabrication of a vibration-driven electromagnetic energy harvester with integrated $\mathrm{NdFeB} / \mathrm{Ta}$ multilayered micro-magnets," J. Micromech. Microeng., vol. 21, no. 9, pp. 095014-1-095014-6, 2011

[63] Q. Zhang, S. J. Chen, L. Baumgartel, A. Lin, and E. S. Kim, "Microelectromagnetic energy harvester with integrated magnets," in Proc. IEEE 16th Int. Solid-State Sensors, Actuat. Microsyst. Conf., Jun. 2011, pp. $1657-1660$.

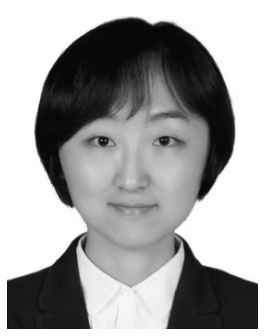

Huicong Liu received the B.Eng. and M.Sc. degrees from the Department of Mechanical Engineering, University of Science and Technology Beijing, Beijing, China, in 2006 and 2008, respectively, and the Ph.D. degree from the Department of Mechanical Engineering, National University of Singapore (NUS), Singapore, in 2013. She was a Research Fellow with the Department of Electrical and Computer Engineering, NUS, from August 2012 to August 2013. Currently, she is an Associate Professor with the Robotics and Microsystems Center, School of Mechanical and Electric Engineering, Soochow University, Suzhou, China. Her research interests are vibration-based MEMS/NEMS energy harvesters and self-powered MEMS devices and systems.

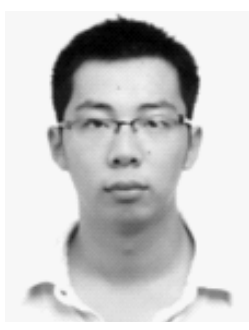

You Qian received the B.Eng. degree from the School of Microelectronics and Solid-state Electronics, University of Electronic Science and Technology of China, Chengdu, China, in 2009, and the M.Sc. degree from the Department of Electrical and Computer Engineering, National University of Singapore (NUS), Singapore, in 2010. Currently, he is a Research Engineer with the Department of Electrical and Computer Engineering, NUS, and is pursuing the Doctorate degree in the same department. He is currently with the Institute of Microelectronics (IME), A*STAR. His research interests focus on NEMS switches.

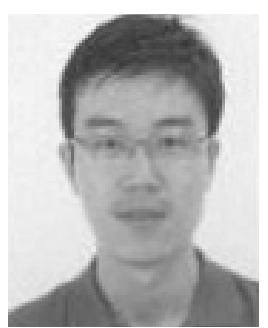

Nan Wang (S'11) received the B.Eng. degree from the Department of Electrical and Computer Engineering, National University of Singapore, Singapore, in 2009, where he is currently pursuing the $\mathrm{Ph} . \mathrm{D}$. degree and is attached to the Institute of Microelectronics, Agency for Science, Technology and Research, Singapore. His research interests include radio-frequency MEMS and phononic crystals.

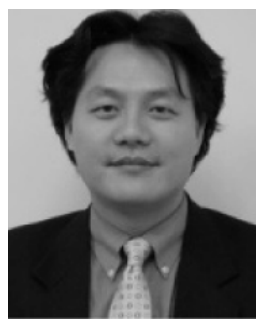

Chengkuo Lee (M'96) received the M.S. degree in materials science and engineering from National TsingHua University, Hsinchu, Taiwan, in 1991, the M.S. degree in industrial and system engineering from Rutgers University, New Brunswick, NJ, USA, in 1993, and the Ph.D. degree in precision engineering from The University of Tokyo, Tokyo, Japan, in 1996. He was a Foreign Researcher with the Nanometerscale Manufacturing Science Laboratory of the Research Center for Advanced Science and Technology, The University of Tokyo, from 1993 to 1996. He was with the Mechanical Engineering Laboratory, AIST, MITI of Japan, as a JST Research Fellow, in 1996. Thereafter, he became a Senior Research Staff Member of the Microsystems Laboratory, Industrial Technology Research Institute, Hsinchu. In 1997, he joined Metrodyne Microsystem Corporation, Hsinchu, and established the MEMS Device Division and the first micromachining fab for commercial purposes in Taiwan. He was the Manager of the MEMS Device Division between 1997 and 2000. $\mathrm{He}$ was an Adjunct Assistant Professor with the Electro-Physics Department, National Chiao Tung University, Hsinchu, in 1998, and an Adjunct Assistant Professor with the Institute of Precision Engineering, National Chung Hsing University, Taichung, Taiwan, from 2001 to 2005. In 2001, he cofounded Asia Pacific Microsystems, Inc., Hsinchu, where he first became Vice President of Research and Development, before becoming Vice President of the Optical Communication Business Unit and Special Assistant to the Chief Executive Officer in charge of international business and technical marketing for the MEMS foundry service. He was a Senior Member of the Technical Staff at the Institute of Microelectronics, A*STAR, Singapore, from 2006 to 2009. Currently, he is an Associate Professor with the Department of Electrical and Computer Engineering, National University of Singapore, Singapore. He is the coauthor of Advanced MEMS Packaging (McGraw-Hill, 2010). He has contributed to more than 190 international conference papers and extended abstracts and 130 peer-reviewed international journal articles in the fields of sensors, actuators, energy harvesting, MEMS, NEMS, nanophotonics, and nanotechnology. He holds nine U.S. patents. 